\title{
La vallée du Coran au Paléolithique supérieur et au Mésolithique
}

Frédéric Surmely

\section{(2) OpenEdition \\ Journals}

Édition électronique

URL : http://journals.openedition.org/adlfi/1432

ISSN : 2114-0502

Éditeur

Ministère de la culture

Référence électronique

Frédéric Surmely, «La vallée du Coran au Paléolithique supérieur et au Mésolithique », ADLFI.

Archéologie de la France - Informations [En ligne], Poitou-Charentes, mis en ligne le 01 mars 2008,

consulté le 19 avril 2019. URL : http://journals.openedition.org/adlfi/1432

Ce document a été généré automatiquement le 19 avril 2019

(c) Ministère de la Culture et de la Communication, CNRS 


\title{
La vallée du Coran au Paléolithique supérieur et au Mésolithique
}

\author{
Frédéric Surmely
}

Identifiant de l'opération archéologique : 204542

Date de l'opération : 2008 (PT)

\section{Introduction}

1 Le présent projet visait à recenser et à effectuer un travail de reconnaissance archéologique, dans une perspective scientifique et conservatoire. Il s'agissait en effet de mettre en évidence le patrimoine préhistorique d'un secteur encore relativement méconnu, malgré le renom mondial d'un site découvert dans la zone (La Roche à Pierrot). Conformément au cahier des charges fixé par le service régional de l'archéologie de Poitou-Charentes, nous avons orienté nos recherches dans deux directions :

- une prospection pédestre des plateaux dominant la vallée ;

- une reconnaissance des escarpements bordant le bas de la vallée. Le SRA nous a demandés de nous limiter à des reconnaissances visuelles, avec des sondages à la tarrière.

L'ensemble des zones reconnues a été enregistré topographiquement avec un GPS, assurant une précision de l'ordre de $2 \mathrm{~m}$.

\section{Prospection pédestre des plateaux}

5 Trente-trois champs labourés ont fait l'objet d'une prospection pédestre systématique, effectuée à la fin du printemps et à la fin de l'automne, afin de profiter des labours, en fonction des cultures pratiquées. Nous avons ainsi prospecté la quasi-totalité de notre zone d'étude, car le reste des parcelles est occupé par des cultures (vignes et champs de cassis) qui ne font pas l'objet de labours. 
6 Tous les champs ont livré des indices isolés de présence préhistorique, sous la forme de quelques pièces lithiques disséminées, ne permettant pas une caractérisation chronologique. Un seul indice de site est rapportable au Paléolithique supérieur (lame à talon punctiforme), sur le plateau dominant immédiatement le site de la Roche à Pierrot.

Quatre concentrations de pièces, trahissant la présence de «sites » du Paléolithique moyen et du Néolithique ont été reconnues. Le nombre de sites découverts n'est pas très important. Ce résultat était prévisible, compte tenu des maigres résultats obtenus par les prospecteurs précédents (G. Couprie et François Blanchet), il améliore cependant la connaissance de la préhistoire de la zone.

\section{Reconnaissance des escarpements rocheux bordant le bas de la vallée}

Les escarpements rocheux ont été profondément bouleversés par les travaux ultérieurs, liés à l'exploitation de la pierre de taille et au fonctionnement des champignonnières.

Le site de la Roche à Pierrot a d'ailleurs été très affecté par ces deux phénomènes.

10 En rive droite du Coran, les bases d'escarpements ont été tronquées par les carrières et la route. En rive gauche, du côté Roche à Pierrot, nous avons prospecté attentivement l'ensemble de la ligne d'escarpement. Trente-trois points d'observation ont été faits, avec des sondages à la tarrière pour reconnaître la nature des formations enfouies et évaluer les perturbations dues aux carrières.

11 Dans la très grande majorité des cas, il n'y a pas de remplissage ancien et le substrat calcaire est immédiatement recouvert par des formations humifères récentes. Les sondages à la tarrière ont permis de mettre cela en évidence.

C'est le cas par exemple du petit abri sous roche (Sc17) dominant le Moulin Neuf, à SaintCésaire.

Seuls trois endroits nous semblent potentiellement intéressants, notamment le présumé abri sous roche effondré situé en contrebas du Paléosite (Sc4 ; X = 378,97456 - 2087,46377). Le sondage à la tarrière bute sur $\mathrm{du}$ rocher, à environ $1 \mathrm{~m}$ de profondeur. Cela peut correspondre au substrat, mais aussi à un surplomb rocheux effondré, qui pourrait alors avoir scellé un remplissage ancien susceptible de contenir des occupations paléolithiques. Un sondage véritable à la mini-pelle, seule façon d'espérer traverser le niveau rocheux, s'avère nécessaire pour résoudre la question. Il s'agit de l'endroit le plus prometteur.

Le recours à la spécialiste de micromorphologie s'est avéré inutile, compte tenu de l'absence de formations anciennes, y compris dans les sondages à la tarrière. De même, l'omniprésence des carrières et champignonnières empêche une analyse géomorphologique précise de la zone, notamment au niveau des versants.

Par ailleurs, une petite enquête auprès de la population a permis de faire l'inventaire d'une découverte de hache polie. Cette dernière est en quartzite. Nous avons prospecté le champ où son inventeur l'avait trouvée, mais sans résultat. 


\section{Conclusion}

16 La recherche menée en 2008, orientée vers la détection des sites de surface sur les plateaux et la reconnaissance des potentialités archéologiques des bases d'escarpements rocheux bordant la vallée, a permis de faire le point sur ces deux aspects. Le potentiel archéologique des plateaux apparait assez limité, pour des raisons liées probablement à la couverture sédimentaire superficielle.

Quatre sites ont pu être découverts, datables du Néolithique sensu lato et du Paléolithique moyen. Un seul indice de présence humaine rapportable au Paléolithique supérieur a été découvert. Les périodes protohistoriques et historiques sont totalement absentes.

Le potentiel des bas de versants apparaît également très limité, pour des raisons qui tiennent essentiellement à l'ampleur des travaux liés à l'exploitation des carrières et des champignonnières. La plupart des bases d'escarpement ont été maintes fois remaniées. En rive droite, il n'existe aucune potentialité. En rive gauche, les sites Sc22, Sc27et surtout Sc4, proches du site de la Roche à Pierrot, pourraient être potentiellement intéressants, mais la technique qui nous était prescrite n'a pas permis de le vérifier.

Nous envisageons donc la poursuite des recherches, avec la possibilité de réaliser des sondages, sur les points Sc22, Sc27 et surtout Sc4 (probable abri sous roche effondré). Le recours à l'engin mécanique est nécessaire pour espérer traverser le niveau rocheux pouvant correspondre à de gros éboulis ou à un plafond rocheux effondré.

21 SURMELY Frédéric

\section{INDEX}

operation Prospection thématique (PRT)

Index chronologique : Mésolithique, Néolithique, Paléolithique moyen, Paléolithique supérieur Thèmes : abri sous roche, agriculture, carrière, exploitation, fonction des sites, géomorphologie, hache polie, industrie lithique, labour, lame, plante alimentaire, route, sondage, topographie, vigne

Index géographique : Poitou-Charentes, Charente-Maritime (17), Saint-Césaire

\section{AUTEURS}

FRÉDÉRIC SURMELY

MCC 